\title{
KAJIAN MAKNA VERBAL DALAM TEMBANG PENGIRING PEMENTASAN TARI MUANG SANGKAL
}

\author{
Adeline Grace M. Litaay \\ Universitas 17 Agustus 1945 Surabaya \\ gracelitaay07@gmail.com
}

\begin{abstract}
ABSTRAK
Tari Muang Sangkal ialah sejenis tari penyambutan bagi tamu agung yang mulanya hanya dapat ditarikan di pendopo atau keraton di Sumenep. Kata Muang Sangkal dalam Bahasa Madura berarti membuang musibah, sial ataupun hal-hal buruk lainnya. Dalam artikel ini akan dibahas makna verbal yang terdapat dalam tembang pengiring Tari Muang Sangkal, dengan menggunakan teori perkembangan tari oleh Sedyawati dan mengaitkannya dengan teori makna verbal serta metode penelitian deskriptif kualitatif. Berdasarkan hasil penelitian, ditemukan bahwa dalam pantun yang dinyanyikan pada tembang pengiring Tari Muang Sangkal terdapat makna verbal berupa suatu ungkapan hati penyair mengenai kisah cintanya yang tidak atau belum mendapatkan respon atau tanggapan dari lelaki pujaannya, walaupun ia telah mengungkapkan perasaannya tersebut secara gamblang.
\end{abstract}

Kata kunci: Tari Muang Sangkal, makna verbal, tembang, pantun

\begin{abstract}
Muang Sangkal dance is a welcome dance for honorable guests which was initially performed only in the pendopo or kraton (palace) of Sumenep. The word Muang Sangkal in Madurese language means getting rid of calamity, bad luck, and other negativities. The study discusses nonverbal communication found in the song accompanying Muang Sangkal dance, applying the theory of dance development by Sedyawati, verbal communication theory and descriptive research method. Based on the findings, the rhyme of the song has a nonverbal meaning about the expression of the poet's anxiety because of her love story in which she has not received the response from the man she loves, though she has already expressed her feelings explicitly.
\end{abstract}

Keywords: Muang Sangkal dance, verbal communication, song accompanying dance, rhyme

\section{PENDAHULUAN}

Manusia adalah makhluk sosial yang akan melakukan interaksi antar satu dengan yang lainnya, baik itu dengan sesama, norma, adat istiadat, pengetahuan bahkan budaya yang ada dalam ruang lingkupnya. Salah satu jenis budaya adalah tarian adat, 
dan tarian adat yang masih berkembang pada saat ini adalah tarian adat Muang Sangkal yang ada di Sumenep, Madura.

Jika mengindahkan budaya maka akan terjadi pergeseran ataupun perubahan nilai luhur yang sudah tidak lagi memperlihatkan jati dirinya sebagai makhluk sosial yang beradab. Perubahan yang terjadi bukan saja berhubungan dengan lingkungan fisik, tetapi juga dengan budaya manusia. Hubungan erat antara manusia dan lingkungan kehidupan fisiknya itulah yang melahirkan budaya manusia. Budaya lahir karena kemampuan manusia mensiasati lingkungan hidupnya agar tetap layak untuk ditinggali waktu demi waktu. Oleh sebab itu dituntut adanya kemampuan, kreativitas, dan penemuan-penemuan baru. Manusia tidak hanya membiarkan diri dalam kehidupan lama melainkan dituntut mencari jalan baru dalam mencapai kehidupan yang lebih manusiawi. Salah satu daerah di Indonesia yang masih menjunjung tinggi kearifan lokal dimaksud ialah masyarakat yang berdomisili di Sumenep.

Secara umum masyarakat di kabupaten ini menggunakan dua bahasa yaitu Bahasa Madura sebagai alat komunikasi sehari-hari dan Bahasa Indonesia sebagai bahasa penghubung bagi pendatang yang sekedar berkunjung ke Kabupaten Sumenep.

Sumenep menyimpan keunikan-keunikan seni, budaya dan tradisi yang masih dipegang teguh serta dijalankan hingga saat ini. Tidak hanya untuk mempertahankan akar budaya, namun juga untuk mematenkan nilai-nilai luhur yang terkandung di dalamnya sebagai satu kesatuan yang tidak boleh terpisahkan dari diri masing-masing masyarakatnya.

Tari Muang Sangkal ialah sejenis tari penyambutan bagi tamu agung yang mulanya hanya dapat ditarikan di pendopo atau keraton di Sumenep. Kata Muang Sangkal dalam Bahasa Madura berarti membuang musibah, sial dan hal-hal buruk. Saat ini, seiring perkembangannya, tari Muang Sangkal sudah dapat ditampilkan di luar pendopo atau keraton dan mempunyai fungsi lain yakni digunakan sebagai tari penjemput tamu terhormat atau tamu-tamu undangan lainnya.

Penelitian ini mengungkap makna verbal yang ada dalam tembang yang mengiringi pementasan tari Muang Sangkal yang merupakan tarian tradisional khas Sumenep. Dalam tembang ini, terdapat pesan-pesan yang mempunyai makna dalam bahasa yang diungkapkannya. 
Sedyawati (1980) menyatakan bahwa tari dapat dideskripsikan sebagai gerak ritmis dari anggota badan, perpaduan pola-pola dalam ruang, gerak spontan yang dipengaruhi emosi yang kuat, paduan gerak-gerak indah dan ritmis, dan gerak terlatih yang disusun secara beraturan untuk menyatakan tindakan dan rasa. Sedyawati (1972) mengatakan bahwa dari sudut bentuk dan perwujudannya, perkembangan tari di Indonesia dapat dibagi atas lima tahap, yaitu:

1. tahap kehidupan terpencil dalam wilayah-wilayah etnik,

2. tahap masuknya pengaruh-pengaruh luar sebagai unsur asing,

3. tahap penembusan secara sengaja batas-batas kesukuan, sehubungan dengan tampilnya nasionalisme Indonesia,

4. tahap gagasan mengenai pengembangan tari untuk taraf nasional,

5. tahap kedewasaan baru yang ditandai oleh pencaharian nilai-nilai di dalam tari itu sendiri.

Berdasarkan beberapa poin di atas, poin dualah yang merupakan unsur penting dari terbentuknya tarian adat Muang Sangkal ini, sedangkan poin lima merupakan unsur lanjutan penilaian yang berhubungan dengan aspek-aspek yang terkandung di dalam tari tersebut, salah satunya yaitu aspek yang mengandung nilai budaya. Bahasa dan kebudayaan merupakan kesatuan yang erat kaitannya. Karena itulah dapat menjelaskan keterkaitan antarkedua unsur ini menjadi semakin rumit. Martin dan Nakayama, (2003) menjelaskan bahwa budaya dapat memengaruhi proses di mana seseorang memersepsikan suatu realita. Semua komunitas dalam suatu tempat selalu mewujudkan apa yang menjadi pandangan mereka terhadap realita melalui budaya. Menurut Geertz (1992) kebudayaan adalah sebuah pola dari makna-makna yang tertuang dalam simbol-simbol yang diwariskan melalui sejarah. Di dalam simbolsimbol tentu menimbulkan pemaknaan masing-masing. Salah satunya berbentuk pesan verbal.

Proses penyampaian pikiran pesan atau perasaan seseorang kepada orang lain dengan menggunakan simbol yang menggunakan satu kala ataupun lebih sebagai media pengantarnya disebut komunikasi verbal. Bahasa adalah media pengantar tersebut. Dalam proses penyampaiannya, bahasa ini mampu menyampaikan dan menerjemahkan pikiran seseorang kepada orang lain. Oleh karena itu bahasa disebut sebagai sistem kode verbal. 


\title{
METODE PENELITIAN
}

Penelitian ini menggunakan metode kualitatif dengan penyajian analisis secara deskriptif, yaitu usaha untuk mengumpulkan, menyusun, dan menginterpretasikan data yang ada dan menganalisa objek yang akan diteliti dengan merujuk pada prosedur-prosedur riset yang menghasilkan data kualitatif. Peneliti berupaya mendeskripsikan makna pesan verbal pada tembang pengiring tari Muang Sangkal pada masyarakat Sumenep. Melalui pendekatan kualitatif, tujuan penelitian pada intinya bertumpu pada usaha untuk mengamati, mengumpulkan, menganalisis, dan menginterpretasi data mengenai makna pesan verbal dalam tembang pengiring tari Muang Sangkal, tarian adat Sumenep.

\section{PEMBAHASAN}

\section{Bait Pertama: Kecilnya Harapan untuk Dapat Merasakan Kebahagiaan Cinta}

\author{
Edhina'ah duh serena \\ (mau ditinggal duh sirihnya) \\ Duh kesana e kabhedde'e \\ (duh kesana (sebuah wadah dari anyaman) mau dibuat wadah) \\ Abdina cora' ta' tekka \\ (saya sepertinya takkan tercapai) \\ Nyare laen ta' kera bhede \\ (cari yang lain tidak mungkin ada)
}

Seperti yang terlihat dalam data yang berupa bagian awal tembang tersebut di atas, tembang pengiring tari Muang Sangkal berisi pantun dengan sajak A-B-A-B. Seperti pantun pada umumnya, maka baris pertama dan kedua berupa sampiran yang tidak memiliki makna khusus. Isi pantun terdapat pada baris ketiga dan keempat, yang menceritakan curahan hati seorang gadis akan kecilnya harapan akan tercapainya kebahagiaan bersama pria yang dicintainya, namun pada bagian ini belum ada penjelasan mengenai sebab mengapa si gadis merasa begitu berkecil hati. Adapun dari baris terakhir dari bait pertama pantun di atas, dapat dilihat bahwa si gadis merasa tidak mungkin ada pria lain yang dapat membuatnya memiliki perasaan yang sama dengan yang dirasakannya kepada laki-laki yang sedang dicintainya sekarang. 


\title{
Bait Kedua: Harapan dan Impian untuk Dapat Bersatu
}

\author{
Roko'oepet ce' nyammana \\ (rokok OEPET enak sekali) \\ Raceghenna neng gheppora \\ (racikannya di Gapura (salah satu kecamatan di Sumenep Utara)) \\ Poko' ghellem epanyamana \\ (asalkan mau akan dibuat nyaman) \\ Neser bhule ekapolonga \\ (aku cinta akan hidup bersama)
}

Jika pada bait pertama, yang terlihat adalah perasaan kecil hati bagai tak berpengharapan, maka pada bait kedua ini, si gadis menyatakan perasaan dan harapannya dengan lebih gamblang. Di baris ketiga, ia seolah mendeklarasikan kesanggupannya untuk membahagiakan si laki-laki dan memberinya kehidupan yang tentram. Untuk itu, yang perlu dilakukan oleh pihak pria hanyalah menerima cintanya. Tidak ada syarat lain yang disebutkan oleh si gadis. Pada baris keempat, ia memperjelas maksudnya: ia akan bahagia sekali jika bisa menghabiskan hidupnya bersama lelaki yang dicintainya. Tidak ada hal spesifik lain yang disebutkannya sebagai kunci kebahagiaan hidupnya selain diterimanya perasaan cintanya agar kemudian dapat mengarungi hidup bersama-sama dengan orang yang dicintainya.

\section{Bait Ketiga: Gundah Gulana Karena Cinta}

Jheng lanjhengan dhewunna nangka

(layang-layang daunnya nangka)

Serkeseran obhi manis

(bagus-bagus ubi manis)

Jheng bejhengan sangghu dhika

(bayang-bayang disangka kamu)

Kerpekkeran sambhi nangis

(memikirkan kamu sambil nangis)

Setelah mengeluhkan kecilnya harapannya untuk bersama dengan pujaan hatinya pada bait pertama dan mengungkapkan harapannya secara lebih gamblang pada bait kedua, maka pada bait ketiga si gadis kembali menceritakan kegalauan yang dirasakan oleh seseorang yang memiliki perasaan cinta yang tidak atau belum berbalas. Cinta yang belum mendapatkan tanggapan akan membuat seorang gadis 
merasa gundah sepanjang waktu. Pada baris ketiga dan keempat bait di atas, si gadis memberikan gambaran perasaannya terhadap si pria, di mana ia selalu sangat merindukan pria yang dicintainya sehingga si pria selalu terbayang olehnya, dan betapa si gadis selalu bersedih hingga meneteskan air mata saat mengingatnya.

\title{
Bait keempat: Kegalauan Hati setelah Mengungkapkan Perasaan
}

\author{
Re sa'are alalakon e depor \\ (seharian kerja di dapur) \\ Terro moleya duh karoma \\ (ingin pulang duh ke rumah) \\ Rekare oca' taloccor \\ (sudah terlanjur aku ngomong) \\ Aduh bhule bheremma'a \\ (lalu aku harus bagaimana)
}

Pada bait keempat, alasan dari segala kebingungan yang dirasakan oleh si gadis menjadi semakin jelas, karena pada baris ketiga dari bait keempat ini si gadis menceritakan bahwa ia telah terlanjur mengungkapkan perasaannya dengan jujur pada si pria, dan dapat disimpulkan bahwa si pria belum memberikan tanggapan apapun. Selain si gadis tidak mengisahkan tentang tanggapan dari lelaki yang dicintainya, absennya respon si lelaki terhadap ungkapan cinta si gadis juga dapat dilihat dari kebingungan yang melandanya. Si gadis tidak tahu harus bersikap bagaimana kepada si pria ataupun harus melakukan apa lagi karena ia sama sekali tidak mendapatkan tanda-tanda ataupun petunjuk mengenai perasaan si lelaki kepadanya.

\section{Bait Kelima: Usaha Meredakan Rindu dan Menghibur Diri Sendiri}

Ngala'ah ponar nambhi' dhemar

(mau mengambil lemper membawa dammar (sejenis lampu minyak)

Se ngalodu' ebeddhei gentong

(yang menelan diletakkan di gentong)

Poko'na ngala' samar

(yang penting mengambil dengan samar-samar/sembunyi-sembunyi)

Mon kerrong jhe' pekker rekong

(kalau kangen jangan sedih) 
Pada bait yang kelima, si gadis penyair mendeskripsikan bagaimana ia berusaha mengatasi segala kegundahannya dengan tetap mengamati pujaan hatinya secara diam-diam dan sepertinya dari jauh, sehingga diharapkan si lelaki pujaan tidak akan mengetahuinya dan tidak merasa terganggu. Dengan cara demikian, setiap kali ia merasa rindu, ia tidak harus terlalu bersedih lagi, karena kerinduannya akan sosok sang pujaan masih dapat teratasi.

\section{Bait keenam: (Ternyata) Masih Belum Dapat Mengatasi Kegelisahan}

Duh ka Gunung......duh ka Gunung ngala'ah powan

(duh kegunung...duh ke gunung mau ngambil powan (sejenis kelapa)

Kope celleng e kabhedde'eh

(botol hitam dijadikan tempat)

Ate bhingung ta' karowan

(hati bingung tidak karuan)

Nape bhule se ekatambhe'eh

(apa yang bisa dijadikan obat)

Bertentangan dengan bait sebelumnya, bait keenam yang sekaligus menjadi bait terakhir dari pantun ini tidak bersifat menghibur atau meredakan perasaan yang bergejolak dari penyair, atau dalam hal ini, si gadis. Dapat dikatakan, bait keenam sebagai penutup pantun tidak memberikan solusi maupun jalan keluar dari seluruh masalah yang telah dikisahkan sejak awal pantun. Sebaliknya, pada isi bait keenam penyair kembali menggambarkan kegelisahan yang dirasakannya, dan pada baris terakhir ia seolah-olah mempertanyakan lagi kepada pembaca (pendengar) apa yang harus ia perbuat untuk mengatasi masalahnya.

\section{PENUTUP}

Berdasarkan hasil penelitian, tembang pengiring Tari Muang Sangkal dari Sumenep berisi pantun yang terdiri dari 6 (enam) bait. Adapun pantun tersebut menceritakan kegundahan hati seorang gadis yang mencintai seorang pria dan telah menyatakan perasaannya tersebut secara terbuka, namun belum mendapatkan tanggapan apapun dari si lelaki, sehingga sang penyair, dalam hal ini, si gadis, merasa bingung, gelisah dan sedih. 


\section{DAFTAR PUSTAKA}

Geertz, C. 1992. Kebudayaan dan Agama. Penerjemah Francisco Budi Hardiman. Kanisius. Yogyakarta.

Martin and Nakayama. 2003. Interncultural Communication in Contexts. The McGraw-Hill Companies. United States.

Sedyawati E. 1977. Tari dalam Sejarah Kesenian Djawa dan Bali. Departemen P \& $\mathrm{K}$.

Sedyawati E. 1980. Tari: Tinjauan dari Berbagai Segi. Jakarta: Pustaka Jaya. 